\title{
Endoscopic ultrasound-guided portal-systemic pressure gradient measurement
}
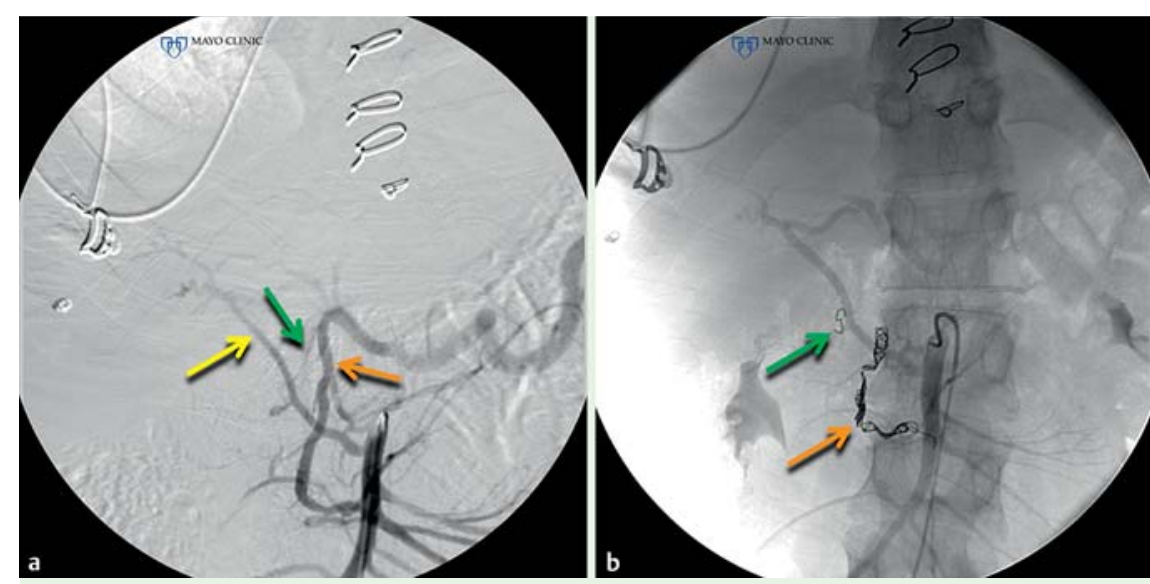

Fig. 1 A 27-year-old man with Noonan syndrome and congenital heart disease presented with recurrent gastrointestinal bleeding, which continued despite cardiac surgery. a Mesenteric angiography demonstrating the gastroduodenal artery (orange arrow), a replaced right hepatic artery (yellow arrow), and a branch communicating the replaced right hepatic artery to the gastroduodenal artery (green arrow). b Given that the periduodenal vessels could not be visualized, coils were prophylactically placed in the gastroduodenal artery (orange arrow) and communicating branch (green arrow).

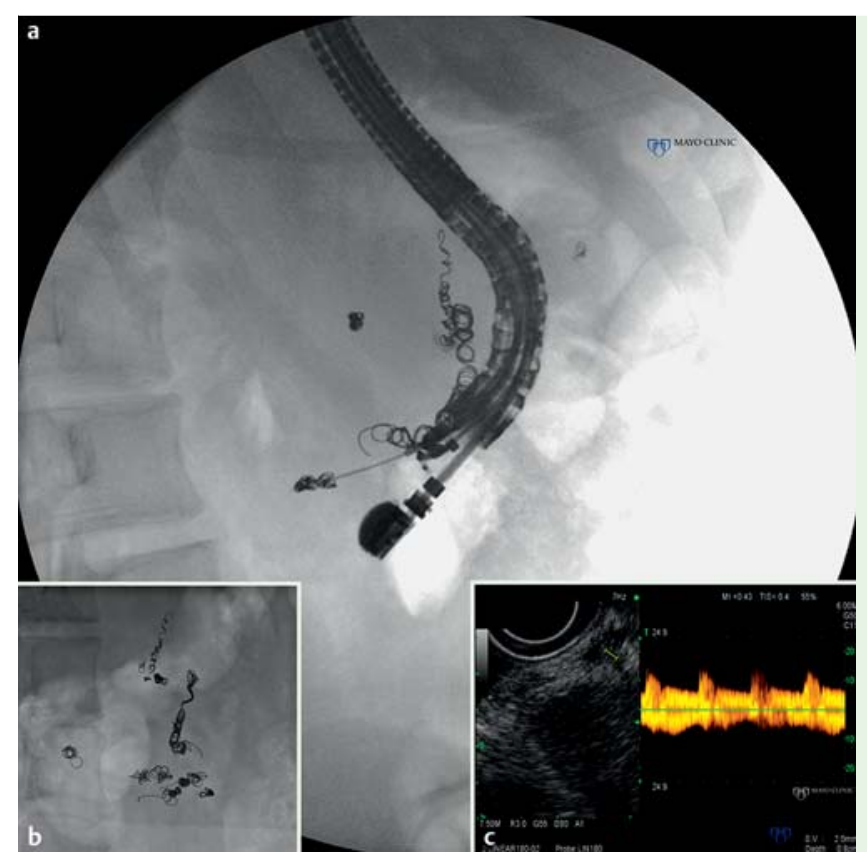

Fig. 2 a, b Endoscopic ultrasound (EUS)-guided coiling with insertion of a total of 20 coils into multiple vascular networks in the 2nd and 3rd portion of the duodenum. c EUS reveals the periduodenal vessels with both an arterial and venous component and a low resistance, high flow waveform.

Portal hypertension is defined by the hepatic venous pressure gradient and is measured via a percutaneous transhepatic route [1]. We describe a novel technique for direct portal pressure measurement using endoscopic ultrasound (EUS). A 27-year-old man with Noonan syndrome and congenital heart disease presented with recurrent gastrointestinal bleeding. EUS revealed an extensive network of periduodenal vessels that were attributed to congestive hepatopathy. However, bleeding continued despite cardiac surgery. Angiography failed to visualize these vessels, but the gastroduodenal artery and adjacent aberrant vessel were embolized prophylactically ( $\bullet$ Fig. 1 ). Clinically significant bleeding continued leading to EUS-guided insertion of 20 coils into the periduodenal vessels. EUS Doppler demonstrated both arterial and venous components ( $\bullet$ Fig. 2). Follow-up imaging revealed a marked improvement of the vascular malformations ( Fig.3a,b) with only occult, but transfusion-requiring bleeding remaining. EUS was repeated with only one vessel large enough to allow coiling.

Given continued uncertainty with regard to the prior hepatic venous pressure gradient and diagnosis, EUS was used to re-measure the portal pressure. The portal vein was accessed using a 22-gauge fine needle aspiration (FNA) needle (Wilson-Cook Medical Inc., Winston-Salem, North Carolina, United States). Portal blood was aspirated through the needle, which was connected to an arterial pressure catheter ( $\bullet$ Fig. 4 a, b, $\bullet$ Fig. 5 a). After calibration, the portal pressure measured $11 \mathrm{mmHg}$, thereby excluding significant portal hypertension. The middle hepatic vein pressure was then measured at $10 \mathrm{mmHg}(\bullet$ Fig. 4 c, d, $\bullet$ Fig. 5 b), confirming a $1 \mathrm{mmHg}$ pressure gradient as recorded by interventional radiology. There was no evidence of bleeding and the hemoglobin was stable 4 days later. Prior EUS-guided portal pressure measurements in porcine models correlated with percutaneous measurements [2-4]. This is the first clinical report demonstrating the feasibility and apparent safety of portal vein and hepatic vein pressure measurements by EUS, thereby allowing diagnosis of arteriovenous malformations as have been reported in Noonan syndrome [5].

\section{Endoscopy_UCTN_Code_TTT_1AS_2AC}

Competing interests: None

\section{Larissa L. Fujii-Lau, Michael D. Leise, Patrick S. Kamath, Ferga C. Gleeson, Michael J. Levy}

Division of Gastroenterology and Hepatology, Mayo Clinic, Rochester, Minnesota, USA

\section{References}

1 Merkel C, Montagnese S. Hepatic venous pressure gradient measurement in clinical hepatology. Dig Liver Dis 2011; 43: 762 767

2 Lai L, Poneros J, Santilli J et al. EUS-guided portal vein catheterization and pressure measurement in an animal model: a pilot study of feasibility. Gastrointest Endosc 2004; 59: 280-283

3 Giday SA, Clarke JO, Buscaglia JM et al. EUSguided portal vein catheterization: a promising novel approach for portal angiography and portal vein pressure measure- 


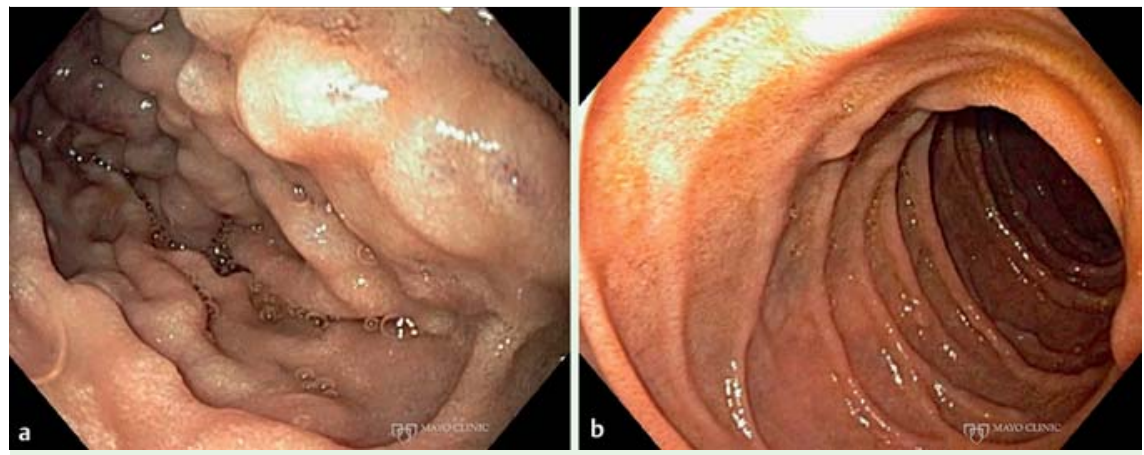

Fig. 3 a Routine endoscopy revealed multiple duodenal serpiginous folds before therapy. $\mathbf{b}$ Their appearance following EUS-guided coil insertion therapy.

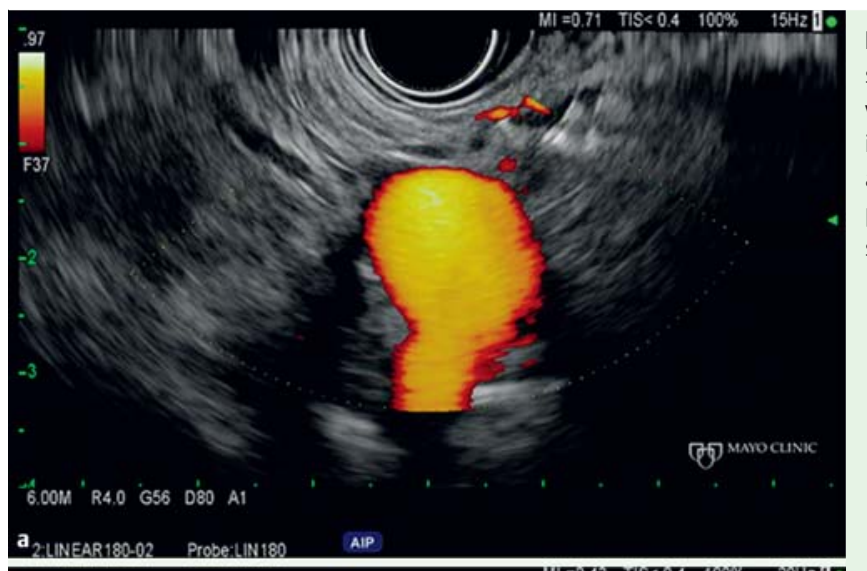

Fig. 4 a EUS demonstrates the portal vein with power Doppler imaging. $\mathbf{b}$ Fine needle aspiration (FNA) needle position during pressure monitoring.

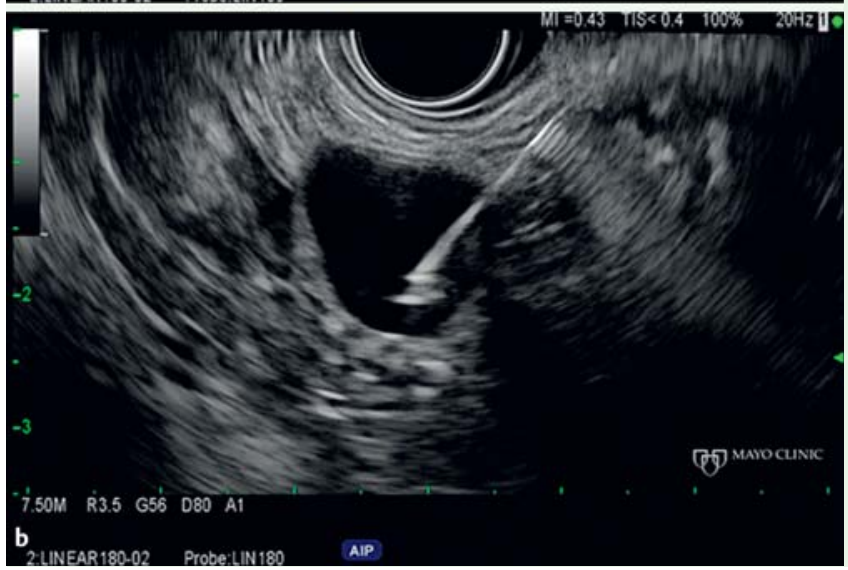




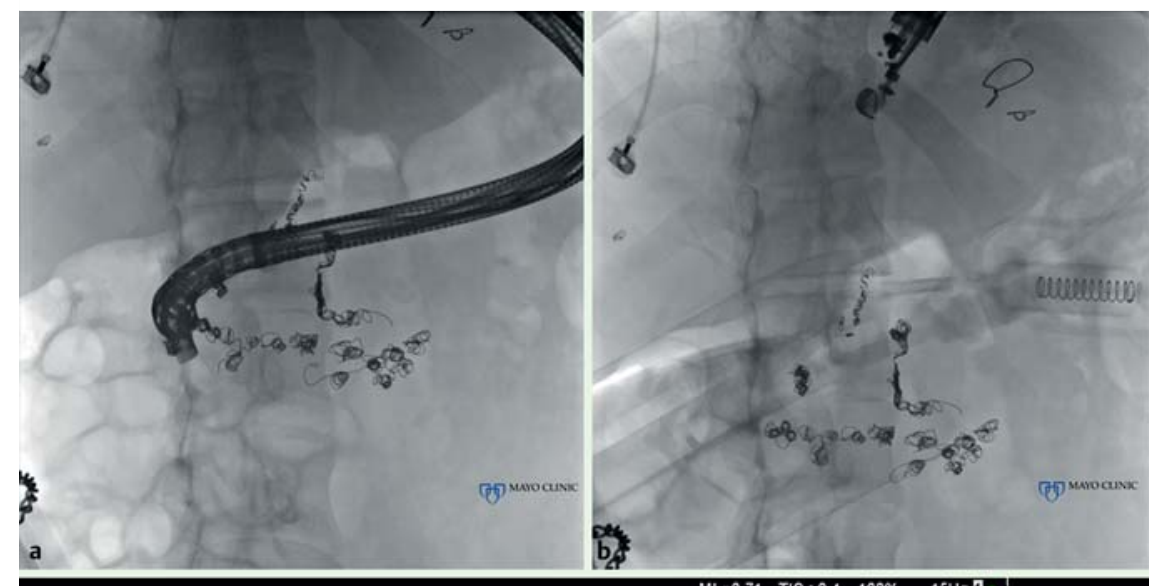

Fig. 5 a Fluoroscopy demonstrating the echoendoscope position during pressure monitoring of the portal vein. $\mathbf{b}$ Fluoroscopy demonstrating the echoendoscope position during pressure monitoring of the middle hepatic vein. $\mathrm{c}$ EUS demonstrates the middle hepatic vein with power Doppler imaging. d FNA needle position during pressure monitoring.
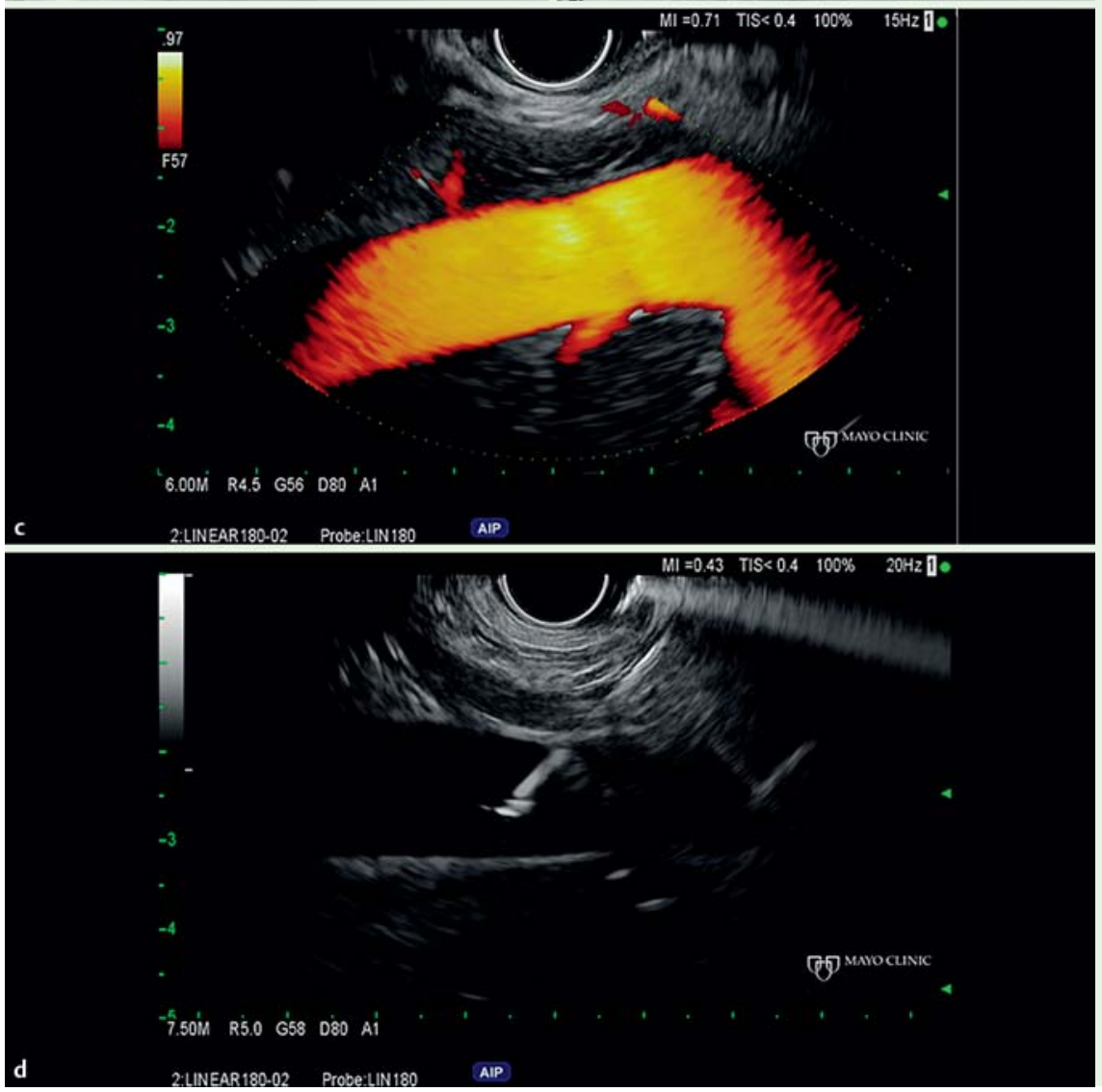

ments. Gastrointest Endosc 2008; 67: 338 342

4 Magno P, Ko CW, Buscaglia JM et al. EUSguided angiography: a novel approach to diagnostic and therapeutic interventions in the vascular system. Gastrointest Endosc 2007; 66: 587-591

5 Yoshino H, Okumachi Y, Akisaki T et al. Bleeding from the small intestine and aortic regurgitation in Noonan syndrome. Intern Med 2011; 50: 2611-2613

\section{Bibliography}

DOI http://dx.doi.org/

10.1055/s-0034-1390845

Endoscopy 2014; 46: E654-E656

(c) Georg Thieme Verlag KG

Stuttgart · New York

ISSN 0013-726X
Corresponding author

\section{Michael J. Levy}

Mayo Clinic

Division of Gastroenterology and Hepatology 2001 st St SW

Rochester

MN 55905

USA

Fax: +1-507-266-3931

levy.michael@mayo.edu 